\title{
Magnifying Endoscopy for Esophageal Ectopic Sebaceous Glands
}

\author{
Mu Song Jeon', Gwang Ha Kim', Dong Young Jeong', Byeong Kyu Park', Moon Won Lee', So-Jeong Lee ${ }^{2}$ and Do Youn Park ${ }^{2}$ \\ Departments of ${ }^{1}$ Internal Medicine and ${ }^{2}$ Pathology, Pusan National University School of Medicine, Busan, Korea
}

Ectopic sebaceous glands are found very rarely in the esophagus; heretofore, several cases have been reported. The sebaceous gland is originally a source of an endodermal origin; however, there have been controversies regarding whether the origin of the esophageal ectopic sebaceous gland is ectodermal or endodermal. Ectopic sebaceous glands of the esophagus usually do not cause symptoms; thus, they are often found incidentally on endoscopy for routine health screening. Endoscopic findings are characterized by single or multiple yellow patches or nodular lesions of various sizes, sometimes with small central openings. We report two cases of esophageal ectopic sebaceous glands found incidentally during endoscopy with magnifying endoscopic findings. The lesions were in the mid-esophagus and lower esophagus, respectively, and both endoscopic findings were similar as multiple yellowish patches or plaques. Magnifying endoscopy revealed the openings of the excretory ducts surrounded by circular microvessels in both cases. Clin Endosc 2018;51:495-497

Key Words: Endoscopy; Esophagus; Sebaceous glands

\section{INTRODUCTION}

The sebaceous gland is closely related to the hair follicle, forming the pilosebaceous apparatus, most commonly in the face and scalp, but occasionally in aberrant areas. Ectopic sebaceous glands were first reported in 1896 as small yellow nodules of the mouth and lips, and they were named as Fordyce's spots. ${ }^{1}$ Since then, they have been reported in the genitalia, eyes and orbits, nipples, palms, soles, and parotid glands. ${ }^{2}$ Ectopic sebaceous glands of the esophagus are a very rare condition. The first report of the gross findings was based on the 200 autopsies in 1962, which revealed ectopic sebaceous glands in approximately $2 \%$ of the total cases; ${ }^{3}$ the first endoscopic observation was reported in 1978. ${ }^{4}$ To date, a total of seven cases have been reported in the Korean literature. ${ }^{5-11}$

Received: November 22, 2017 Revised: December 20, 2017

Accepted: December 27, 2017

Correspondence: Gwang Ha Kim

Department of Internal Medicine, Pusan National University School of Medicine, 179 Gudeok-ro, Seo-gu, Busan 49241, Korea

Tel: +82-51-240-7869, Fax: +82-51-244-8180, E-mail: doc0224@pusan.ac.kr

ORCID: https://orcid.org/0000-0001-9721-5734

(c) This is an Open Access article distributed under the terms of the Creative Commons Attribution Non-Commercial License (http://creativecommons.org/ licenses/by-nc/3.0) which permits unrestricted non-commercial use, distribution and reproduction in any medium, provided the original work is properly cited.
Herein, we report two cases of esophageal ectopic sebaceous glands found incidentally during endoscopy with magnifying endoscopic findings.

\section{CASE REPORTS}

\section{Case 1}

A 63-year-old man visited our hospital for evaluation of dysphagia and regurgitation. He did not drink or smoke. On upper endoscopy, multiple yellowish patches were found in the lower esophagus (Fig. 1A). On magnifying endoscopy with narrow-band imaging (ME-NBI), the excretory ducts of the sebaceous glands were slightly protruded and surrounded by circular microvessels (Fig. 1B). The endoscopic biopsy specimen showed large and polygonal, clear cells with vacuolated cytoplasm within the squamous epithelium (Fig. 1C). Ectopic sebaceous glands in the esophagus were diagnosed on the basis of the endoscopic and histopathological findings.

\section{Case 2}

A 47-year-old man was referred to our hospital for resection of a $1.0 \mathrm{~cm}$-sized gastric polyp found during screening endoscopy. He did not drink or smoke. His medical history was 
unremarkable, and no symptoms other than mild dyspepsia were noted. Endoscopic mucosal resection was performed for the gastric polyp, which was pathologically diagnosed as a hyperplastic polyp. At that time, several yellow plaques were identified in the mid-esophagus (Fig. 2A). ME-NBI showed slightly protruded excretory ducts of the sebaceous glands, which were surrounded by circular microvessels (Fig. 2B). The biopsy specimen exhibited microvesicular vacuolization with small dark nuclei (Fig. 2C). These lesions were diagnosed as esophageal ectopic sebaceous glands based on the endoscopic and histopathological findings.

\section{DISCUSSION}

Ectopic sebaceous glands of the esophagus are very rare findings and found incidentally on endoscopy. Recently, reports of cases with esophageal ectopic sebaceous glands have been increasing owing to an increase in heath-checkup endoscopy. According to a study of 215,046 patients in Taiwan, the incidence and prevalence rates were $0.00465 \%$ and 0.41 per year, respectively, ${ }^{12}$ and in a recent Korean literature, ectopic esophageal sebaceous glands were identified in $0.05 \%$ of asymptomatic subjects. ${ }^{13}$

The origin of ectopic sebaceous glands in the esophagus has not been elucidated. The most interesting aspect is that the esophagus originates from the endoderm, whereas the sebaceous gland is the structure of the ectodermal origin. The mechanism of their development is unclear; however, it is presumed to be caused by congenital misplacement or metaplastic change. Since esophageal ectopic sebaceous glands have never been reported in children and are more prevalent in older individuals, ${ }^{14,15}$ the metaplastic theory is more plausible. Some authors have argued that an association with reflux esophagitis and smoking and drinking habits exists ${ }^{2,10}$ but have not yet shown any clear correlation. Our patients did not drink or smoke, and endoscopic findings suggesting reflux esophagitis were not found. Considering these, there is limited evidence favoring the roles of irritations, such as gastroesophageal reflux or smoking/alcohol consumption, on the occurrence of esophageal ectopic sebaceous glands. Although our patients had non-specific symptoms, such as mild dyspepsia or reflux symptoms, the association between these symptoms and the development of ectopic sebaceous glands seems to be weak.
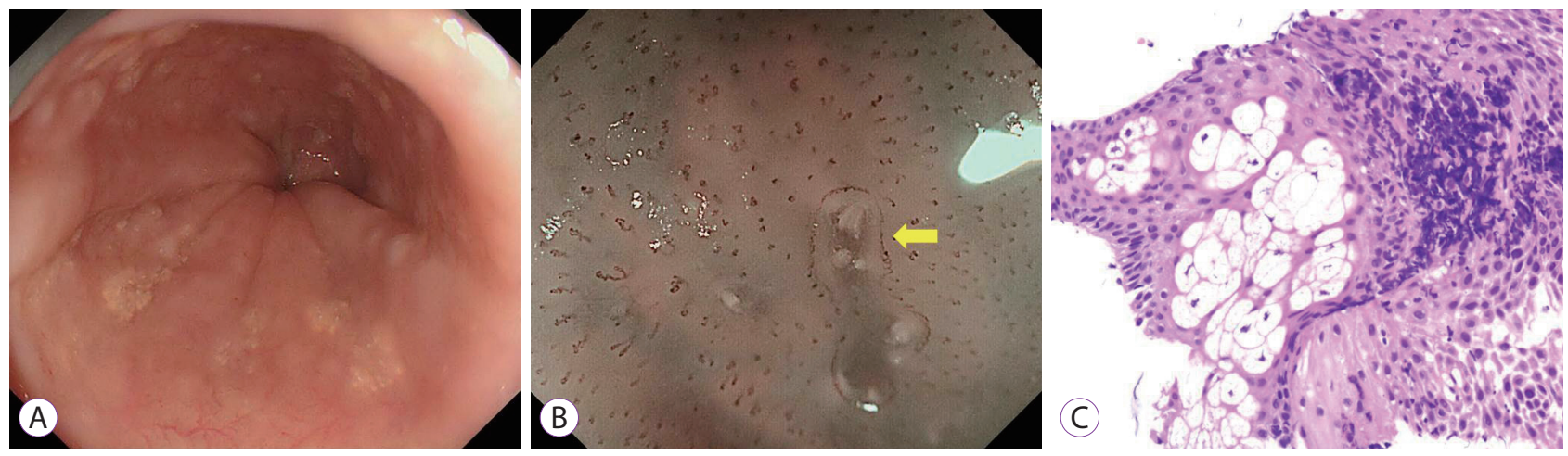

Fig. 1. (A) Upper endoscopy reveals multiple yellowish patches in the lower esophagus. (B) On magnifying endoscopy with narrow-band imaging, the excretory ducts of the sebaceous glands are slightly protruded and surrounded by circular microvessels (arrow). (C) Endoscopic biopsy reveals large and polygonal, clear cells with vacuolated cytoplasm within the squamous epithelium (hematoxylin and eosin, $\times 400$ ).
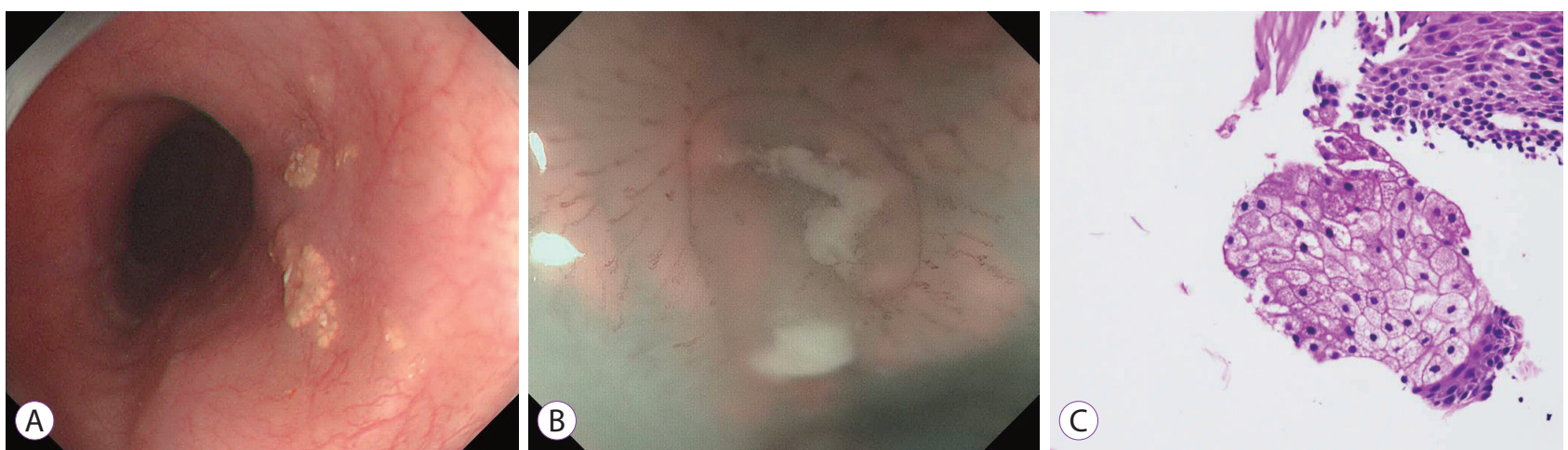

Fig. 2. (A) Upper endoscopy reveals several yellow plaques in the mid-esophagus. (B) Magnifying endoscopy with narrow-band imaging shows the excretory ducts of the sebaceous glands surrounded by circular microvessels. (C) Endoscopic biopsy reveals aggregates of polygonal cells with small central nuclei and abundant clear granular cytoplasm with foam-like fat droplets (hematoxylin and eosin, $\times 400$ ). 
The endoscopic findings may appear as yellowish papules or nodules with an irregular surface, occasionally with a small tubular opening in the center, which may appear as a small white protuberance. ${ }^{10}$ The size and number of the lesions vary, ranging from 1 to $20 \mathrm{~mm}$ and from single to more than a hundred, respectively. ${ }^{16,17}$ The most prevalent anatomical location has not been established; however, to date, ectopic sebaceous glands have been reported to occur most frequently in the mid-to-lower esophagus. In our cases, the lesion in the first case was in the mid-esophagus, and that in the second case was in the lower esophagus. Their endoscopic findings were similar as multiple yellowish patches or plaques. A differential diagnosis is needed in the presence of other yellowish lesions in the esophagus, such as carcinoid tumor, granular cell tumor, or xanthoma. Xanthoma is most likely to be confused with ectopic sebaceous glands. Macroscopically, esophageal xanthoma often manifests as white-to-yellowish, granular or verruciform lesions. ${ }^{18}$ Therefore, it is not easy to distinguish xanthoma from ectopic sebaceous glands before the confirmation of endoscopic biopsy; at that time, ME-NBI might help distinguish them. In fact, the excretory ducts of the sebaceous glands were seen very clearly on ME-NBI, and they were surrounded by circular microvessels in both cases. The circular microvessels seen on ME-NBI may have occurred because of the displacement of the vessels by the presence of subepithelial components (ectopic sebaceous glands) in the lamina propria mucosae. To our knowledge, this is the first report on ME-NBI for esophageal ectopic sebaceous glands.

In several studies, esophageal ectopic sebaceous glands were followed up for years, and there were some fluctuations in their appearance; nevertheless, no change in the number and size of the lesions was eventually observed. ${ }^{15,19,20}$ In addition, no report on malignant transformation has been conducted to date. Therefore, they usually have a good prognosis and do not require treatment.

In conclusion, we report two rare cases of esophageal ectopic sebaceous glands with characteristic ME-NBI findings. On endoscopy, the esophageal ectopic sebaceous glands appeared as yellowish papules or nodules in the mid-to-lower esophagus, and on ME-NBI, the excretory ducts of the sebaceous glands were surrounded by circular microvessels. These characteristic features are helpful in differentiating ectopic sebaceous glands from other yellowish lesions, such as carcinoid tumor, granular cell tumor, or xanthoma.
Conflicts of Interest

The authors have no financial conflicts of interest.

\section{REFERENCES}

1. Fordyce JA. A peculiar affection or the mucous membrane of the lips and oral cavity. Arch Dermatol 1996;132:1285.

2. Bertoni G, Sassatelli R, Nigrisoli E, Conigliaro R, Bedogni G. Ectopic sebaceous glands in the esophagus: report of three new cases and review of the literature. Am J Gastroenterol 1994;89:1884-1887.

3. De La Pava S, Pickren JW. Ectopic sebaceous glands in the esophagus. Arch Pathol 1962;73:397-399.

4. Ramakrishnan T, Brinker JE. Ectopic sebaceous glands in the esophagus. Gastrointest Endosc 1978;24:293-294.

5. Bae JY, Chon CY, Kim H. Sebaceous glands in the esophagus. J Korean Med Sci 1996;11:271-274.

6. Kim SM, Im EH, Jung SH, et al. A case of ectopic sebaceous glands in the esophagus. Korean J Gastrointest Endosc 2005;31:320-322.

7. Shin JH, Jung JH, Choi HJ, Yoo J, Kang SJ, Lee KY. Ectopic sebaceous glands in the esophagus: a case report. Korean J Pathol 2006;40:448-451.

8. Kim YS, Jin SY, Shim CS. Esophageal ectopic sebaceous glands. Clin Gastroenterol Hepatol 2007;5:A23.

9. Park HB, Cho HG, Kim YJ, et al. A case of ectopic sebaceous glands in the esophagus. Korean J Gastrointest Endosc 2010;41:155-158.

10. Kim TH, Song JH, Kim TH, et al. A case of ectopic sebaceous glands in the esophagus. Korean J Helicobacter Up Gastrointest Res 2012;12:249251.

11. Lee SH, Lee DJ, Kim KM, Kim KN, Kang JK. Ectopic sebaceous glands in the oesophagus: a case report and review of literature. Scott Med J 2014;59:e1-e5.

12. Chiu KW, Wu CK, Lu LS, Eng HL, Chiou SS. Diagnostic pitfall of sebaceous gland metaplasia of the esophagus. World J Clin Cases 2014;2:311315.

13. Park A, Lee JH, Park A, et al. Prevalence rate and clinical characteristics of esophageal ectopic sebaceous glands in asymptomatic health screen examinees. Dis Esophagus 2017;30:1-5.

14. Rector LE. Aberrant mucosa in the esophagus in infants and in children. Arch Pathol 1941;31:285-294.

15. Wang WP, Wang WS, Tsai YC. Multiple tiny ectopic sebaceous glands discovered throughout entire esophageal tract. Dig Dis Sci 2009;54:27542757.

16. Hoshika K, Inoue S, Mizuno M, Iida M, Shimizu M. Endoscopic detection of ectopic multiple minute sebaceous glands in the esophagus. Report of a case and review of the literature. Dig Dis Sci 1995;40:287-290.

17. Wei IF, Chang CC, Fang CL, et al. Education and imaging. Gastrointestinal: ectopic sebaceous glands in the esophagus. J Gastroenterol Hepatol 2008;23:338.

18. Bang CS, Kim YS, Baik GH, Han SH. Xanthoma of the esophagus. Clin Endosc 2014;47:358-361.

19. Nishisaki H, Yasutake K, Nakashima T, et al. Five cases with ectopic esophageal sebaceous glands. Dig Endosc 1997;9:207-212.

20. Fukuchi M, Tsukagoshi R, Sakurai S, et al. Ectopic sebaceous glands in the esophagus: endoscopic findings over three years. Case Rep Gastroenterol 2012;6:217-222. 